\title{
LOS DIVIDENDOS DE LA PRESIÓN POLÍTICA: LA LIGA MARÍTIMA ESPAÑOLA (1899-1910)*
}

\author{
MARTÍN RODRIGO Y ALHARILLA \\ Universitat Pompeu Fabra
}

\begin{abstract}
RESUMEN
En el marco del debate sobre las relaciones entre poder económico y poder político, en el artículo se analiza la labor que un poliédrico grupo de presión, como fue la Liga Marítima Española, desarrolló en la primera década del siglo XX, prestando atención a su capacidad para condicionar tres variables diferentes de la política económica del período (las primas a la marina mercante, la protección a la producción hullera y la política estatal en materia de construcciones navales) así como a los instrumentos de que se dotaron sus dirigentes para hacer avanzar sus propuestas.
\end{abstract}

Palabras clave: grupo de presión, navieras, astilleros, Restauración

\begin{abstract}
This paper analyzes the role of a very multifaceted lobby group, the Spanish Maritime League, in the context of the relationships between the economic and

\footnotetext{
${ }^{*}$ Una primera versión de este trabajo se presentó en el Seminario de Historia de la Fundación Ortega y Gasset, cuyos asistentes aportaron diversas sugerencias que espero haber sabido recoger. Igualmente debo agradecer las aportaciones que Jesús Millán, Josep María Fradera, Ignacio Arana y los evaluadores anónimos de la Revista hicieron a un borrador anterior de este artículo. Las deficiencias, por supuesto, son de mi exclusiva responsabilidad.

a Departamento de Humanidades, Ramon Trias Fargas 25, 08005 Barcelona. martin.rodrigo@upf.edu
} 
the political spheres during the first decade of the twentieth century. It specially focuses in the League's ability to influence three important economic variables of the period (public subsidies to the merchant fleet, the protectionist policy towards coal production, and the policies in naval production) as well as in the strategies followed by its leaders to move forward their proposals.

Keywords: lobby, shipping companies, shipyards JEL Classification: N43

\section{INTRODUCCIÓN}

El análisis de las formas con que la actividad de los grupos de presión pudo condicionar la política económica de los sucesivos gobiernos de la Restauración no ha estado exento de polémica historiográfica. En general, el ejercicio del poder en esa etapa de nuestra historia ha sido objeto de controversia entre los investigadores sociales. Algunos autores, básicamente desde la historia política, han insistido en la autonomía del poder político frente a los intereses económicos, un campo en que podríamos situar, con diferentes matices, los trabajos de José Varela Ortega, Ignacio Arana, Mercedes Cabrera y Fernando del Rey. Tomando también como punto de partida la preeminencia de la política, trabajos recientes de diversos autores han conformado una fecunda línea historiográfica, especialmente en el estudio de la Restauración, preocupada por revalorizar el papel del parlamento en la vida política del país, por renovar tanto los análisis del clientelismo político como los estudios biográficos de los líderes más destacados, así como por analizar los comportamientos políticos de las agrupaciones empresariales ${ }^{1}$. En esa línea, probablemente la formulación más completa y acabada publicada recientemente sobre el poder de los empresarios en la España del siglo XX ha sugerido que su capacidad de influencia en la vida política del país ha sido más limitada de lo que otros autores como Vicens Vives o Tuñón de Lara habían apuntado años antes².

Aunque algunos historiadores económicos, como Juan Pan-Montojo y Núria Puig, coinciden con esos planteamientos al cuestionar la capacidad de presión de los agentes económicos en la configuración de la política arancelaria de la Restauración, la mayor parte de los historiadores económicos que han trabajado al

\footnotetext{
${ }^{1}$ A título de ejemplo, y sin voluntad exhaustiva, encontramos los trabajos de Varela Ortega (1977 y 1978), la propia Cabrera (1983, 1997 y 1998), de Del Rey (1992), de Moreno Luzón (1995 y 1998), de González Hernández (1997), de Sierra (1996) y de Martorell (2000), así como los estudios incluidos en la compilación de Robles Egea (1996).

${ }^{2}$ Cabrera y Del Rey (2002). Para la visión contraria véanse Vicens Vives (1969) o Tuñón de Lara (1971).
} 
respecto -como Serrano Sanz, Escudero o Valdaliso- han insistido, por el contrario, en la intensa comunicación entre poder político y poder económico durante dicho período, resaltando la capacidad de los grupos de presión para condicionar la política económica en la Restauración ${ }^{3}$. Por otro lado, Pedro Fraile, en un trabajo centrado en la primera mitad del siglo XX, entiende la protección gubernamental «como un fenómeno endógeno al mismo sistema industrial [...] determinado por el equilibrio de fuerzas entre 'lobbies' o grupos de presión», y atribuye a los 'lobbies' industriales haberse convertido en «uno de los artífices más importantes [...] de la estrategia económica que acabó separando a la economía industrial española del mercado internacional ${ }^{4}$. El trabajo de Fraile ha merecido, sin embargo, diferentes tipos de críticas. Para Pan-Montojo y Puig, Fraile ofrece «hipótesis vagas, sin ningún análisis de cómo eran o podían ser [...] la[s] relacion[es] entre grupos de interés, representación, clase política y Administración ${ }^{5}$. Por otro lado, Jordi Nadal y Carles Sudrià opinan que Fraile yerra al centrar su análisis de las causas del atraso económico español en el lado de la oferta, cuestionando que la estructura oligopolística -atribuida por Fraile al conjunto de la economía española- afectase por igual a todos los sectores productivos del país. Por su parte, Marcela Sabaté, en su análisis del arancel de 1906, cuestiona otra de las ideasfuerza de Fraile: la pretendida captura del Estado por parte de los industriales no se corresponde con los matices y cambios que se aprecian al estudiar la política económica del período ${ }^{6}$. No obstante, dichas críticas no niegan la existencia de una protección indiscriminada o integral a partir del arancel de 1906. Así, parece difícilmente cuestionable que en los años que enmarcan nuestro análisis se fue conformando un marco legislativo que propició tanto la reserva del mercado nacional para los productores españoles como una política de subsidios públicos vía subvenciones o vía aranceles- a determinados sectores, como el naviero y el de la construcción naval ${ }^{7}$. A este marco legislativo no resultaron ajenas ni las campañas ni las presiones encabezadas por diferentes corporaciones, articuladas con la expresa voluntad de actuar como grupos de presión.

La presente reflexión se ocupa de analizar el papel que pudo desempeñar uno de estos grupos, la Liga Marítima Española, en la definición de diferentes variables de la política económica del período. Para ello describiré someramente, en primer lugar, la marcha de la entidad en sus primeros años, destacando el complicado y a la vez dilatado proceso seguido por sus dinamizadores hasta conseguir

\footnotetext{
${ }^{3}$ Pan-Montojo y Puig (1995), Serrano Sanz (1987), Escudero (1990), Valdaliso (1990).

${ }^{4}$ Fraile (1991, p. 29), sirviéndose del instrumental analítico de Olson (1992).

${ }^{5}$ Pan-Montojo y Puig (1995, p. 253).

${ }^{6}$ Nadal y Sudrià (1993), Sabaté (1996, pp. 209-210).

7 Véase una visión a vuelapluma de dicho fenómeno en Pelechá (1987, esp. pp. 15-28). Un buen resumen de sus antecedentes, en Pan-Montojo (1998).
} 
un consenso suficientemente amplio entre los diversos agentes del sector. A continuación, me detendré en el análisis de dos de las piezas legislativas emanadas durante el «gobierno largo» de Maura, vinculadas ambas a las peticiones de la Liga, como fueron: (1) la Ley de la Escuadra y (2) la Ley de Comunicaciones Marítimas. En tercer lugar, extenderé mi análisis a la labor de una sociedad filial de la Liga instituida para la búsqueda de aranceles que protegiesen al carbón español. Por último, ofreceré un marco explicativo global sobre la capacidad de la Liga para condicionar aspectos concretos de la política del sector.

\section{BUSCANDO EL ASENTIMIENTO COLECTIVO}

La primera idea de constituir una liga naval en España surgió en la primavera de 1899 a partir de la propuesta de un oficial de la Armada, Adolfo Navarrete Alcázar, quien, inspirándose en los ejemplos británico, alemán, italiano y francés, planteó a través de la prensa marítima del país la necesidad de formar un «movimiento de regeneración marítima», movimiento que se acabó concretando, inicialmente, en una reunión preparatoria celebrada el 9 de junio de 1900 con la asistencia de unas cincuenta personas, entre las que sólo había tres empresarios navieros: Eduardo Aznar de la Sota, Eduardo Ybarra y Claudio López Bru ${ }^{8}$. No fue, sin embargo, hasta el 15 de noviembre de 1900 cuando acabaron de constituirse los órganos directivos de la nueva Liga Marítima Española ${ }^{9}$. En cierta medida, puede afirmarse que en el nacimiento de dicha entidad confluyeron tres proyectos, diferentes aunque complementarios. Un primer proyecto - personificado en Adolfo Navarrete- surgido entre oficiales de la Armada preocupados por el impacto que las derrotas de Cavite y de Santiago estaban teniendo para el poder naval español, y que fueron quienes lanzaron la idea de creación de la Liga; un segundo -del que eran exponentes tanto Antonio Maura como Joaquín Sánchez de Toca- encarnado por individuos preocupados, como los marinos pero en clave esencialmente política, por la supuesta decadencia naval del país en aras de la definición de un determinado proyecto nacional, y un tercero -representado singularmente por el Marqués de Comillas, uno de los dos vicepresidentes de la entidad-, emanado entre aquellos navieros interesados en alcanzar mayores cotas de protección para la marina mercante española y, en general, para los diferentes sectores de la economía marítima del país ${ }^{10}$. La coincidencia de Comillas y su naviera, la

${ }^{8}$ Revista General de Marina 1899 (abril), pp. 492-494; (agosto), pp. 267-270; 1900 (abril), pp. 369-370; (mayo), p. 497; (junio), pp. 689-694; (julio), pp. 92-96.

${ }^{9}$ En el Patronato de la Liga se dieron cita buena parte de los líderes políticos dinásticos del momento: Francisco Romero Robledo, Faustino Rodríguez San Pedro, Germán Gamazo, José Canalejas, Segismundo Moret, José Echegaray, Gaspar Núñez de Arce, Carlos O’Donnell Abreu y el Conde de Pere Camps. 
Compañía Transatlántica, con la filosofía que alentaba la nueva entidad era tal que decidieron transformar en 1902 el órgano oficioso de propaganda de la Trasatlántica, la Revista de Navegación y Comercio, para crear Vida Marítima, el portavoz oficial de la Liga. El Marqués de Comillas no fue, sin embargo, el único empresario que dirigió los asuntos de la entidad; el naviero barcelonés Federico Nicolau, por ejemplo, pasó a presidir la sección de asuntos políticos, económicos y militares; el naviero sevillano Tomás Ibarra hizo lo propio con la de navegación y comercio; José M. Cornet -director de La Maquinista Terrestre y Marítimapresidió a su vez la sección de construcciones y armamento marítimo, mientras que la de pesca e industrias auxiliares quedaba encabezada por el armador guipuzcoano José Arístegui ${ }^{11}$.

Correspondió, sin embargo, a dos políticos, Antonio Maura y Joaquín Sánchez de Toca, encabezar públicamente la primera Junta Central de La Liga. Como ha señalado María Jesús González, la actividad política del primero se había iniciado, precisamente, al aceptar en 1879 el encargo de numerosas corporaciones de Palma para la defensa de «una serie de propuestas en torno a las primas a la construcción y la restauración del derecho diferencial de bandera para favorecer a la navegación nacional $»^{12}$. Desde aquel momento, el entonces liberal Maura mostró siempre una notable preocupación por la política naval del país, identificándose plenamente con los principios de la Liga, entidad que no dudó en presidir. Si en la asamblea de noviembre de 1900 se había definido a la nueva entidad como un grupo de interés decidido, en palabras de sus fundadores, a «representar ante la opinión y los poderes públicos las aspiraciones, y promover por todos los medios legítimos de propaganda e influencia el fomento de la vida marítima nacional», Antonio Maura insistió en la misma línea haciendo, en el primer número de Vida Marítima, un llamamiento a la organización «porque ningún otro orden de intereses colectivos está tan desatendido y hasta ignorado como el conjunto colosal de España en los mares [...] [lo que] redobla la necesidad de habilitarse y organizarse» ${ }^{13}$. Tras la elaboración de

${ }^{10}$ Así, J. Zamora (1996, p. 58) afirma que, tras su creación, «en los años siguientes, con toda razón, la Liga (LME) fue considerada por los sectores civiles como un instrumento de dominio cultural y político de la Armada sobre todo el universo marítimo». Otros autores, sin embargo, no han dudado en caracterizar a la Liga Marítima como auténtico grupo de presión. Por ejemplo, García Delgado, Roldán y Muñoz (1973), Santos Pastor (1982), recogido en Zamora (1996, p. 60), o Pan-Montojo (1998, p. 317)

${ }^{11}$ Bordejé (1978, p. 40)

12 González Hernández (1997, p. 14). Sobre la política naval de Maura, véanse también pp. 263-272. Vid. asimismo Cabrera (1988, p. 56). Sánchez de Toca, por su parte, había publicado apenas unas semanas después de la derrota naval de Santiago de Cuba una monografía que acabaría siendo, al decir de Valdaliso y López Losa (2001, p. 428) «la obra quizás más influyente sobre la historiografía naval y marítima de España hasta fechas muy recientes». Sobre la dimensión naval de sus preocupaciones, véanse Sánchez de Toca (1898, 1900 y 1903)

13 Vida Maritima $\mathrm{n}^{\circ} 1$ (10-1-1902), pp. 2-3. El subrayado es mío. 
unas primeras Bases para un Proyecto de Ley de Protección a las Industrias Marítimas Nacionales, la Junta de la Liga intentó conseguir el más amplio consenso entre los agentes del concierto marítimo, buscando formulaciones concretas para las peticiones del sector. A tal efecto, convocaron un Congreso Nacional -celebrado finalmente en Madrid en junio de 1901- en el que los diferentes actores de la vida marítima española dieron los primeros y aún genéricos pasos en el consenso de dichas propuestas $^{14}$. Ahora bien, no fue hasta finales de noviembre de 1903 -casi tres años y medio después del Congreso- cuando los dirigentes de la Liga pudieron entregar en las Cortes un texto suficientemente consensuado como «resultado de la información extraparlamentaria verificada por ella $[y]$ como resumen y término de un trabajo iniciado en 1901 a raíz del Congreso Marítimo» ${ }^{15}$.

En ese tiempo, los dirigentes de la Liga habían buscado el «asentimiento colectivo» de los diferentes actores implicados, persiguiendo siempre «fórmulas de conciliación entre los diversos intereses [...] a fin de que las gestiones de la Liga sean eficaces por la suma de autoridades que la apoyen». De hecho, la Liga Marítima fue siempre del parecer que: «cuantas más entidades marítimas se agrupen en la Liga para dar impulso al proyecto [...] lo harán más viable y facilitarán considerablemente la acción del Estado». Decían sus dirigentes que «el procedimiento seguido por la Liga tiende a evitar [las divergencias públicas] [...] porque facilita la controversia dentro de la sociedad y las soluciones de equidad entre todos los intereses de las industrias marítimas nacionales $)^{16}$. Habían aprendido la lección del fracaso cosechado por la Asociación de Navieros y Consignatarios de Barcelona, entidad patronal nacida en 1876, incapaz de conseguir que prácticamente ninguna de sus demandas tomase cuerpo normativo, dada su incapacidad de sumar esfuerzos más allá del protagonismo de los navieros de altura de Barcelona secundados por unos cuantos armadores, también de altura, de Cádiz y Santander ${ }^{17}$.

El esfuerzo por incorporar al tren de la Liga al máximo número de actores políticos y económicos obligó a la Junta de la entidad a lidiar con los diversos intereses de los diferentes agentes implicados, especialmente con los navieros vizcaínos organizados en la Asociación de Navieros de Bilbao, quienes habían reiterado su preocupación por un proyecto que daba prioridad a las demandas e intereses de los empresarios siderúrgicos y constructores navales. De hecho, la coyuntura en que la Liga empezó a hacer públicas sus demandas concretas de protección en favor de la marina mercante se caracterizaba por una fuerte caída de fletes. Dicha caída sacudía desde 1901 al mercado internacional, y para los navieros es-

\footnotetext{
${ }^{14}$ Información de la Liga (1903).

15 Fundación Maura, Fondo Antonio Maura Montaner, legajo 404/1, carpeta 1: «Ley de Comunicaciones Marítimas. Antecedentes cronológicos del Proyecto». Se trata del trabajo citado en la nota anterior.

${ }^{16}$ Vida Maritima no 53 (20-6-1903), pp. 331-332; no 58 (20-7-1903), pp. 390-392.

17 Rodrigo (2004)
} 
pañoles comportaba diferentes consecuencias negativas: el descenso de los beneficios -cuando no el registro de pérdidas-, la brusca contracción de la inversión en el sector, la quiebra de algunas empresas -o la fusión de otras para evitar su desaparición- y la reducción del capital de las compañías ${ }^{18}$. En ese contexto, Ramón de la Sota, sirviéndose de la Asociación de Navieros de Bilbao, instituyó una nueva entidad corporativa, la Asociación General de Navieros Españoles. En un congreso celebrado en Madrid en noviembre de 1903, los representantes de las principales firmas navieras del país decidieron constituir la nueva entidad para defender más eficazmente sus intereses en tanto que navieros, algo diluidos en el seno de la Liga Marítima. No obstante, su objetivo no era aparecer como una alternativa a la Liga, sino como una iniciativa complementaria. En esa reunión se eligió una Junta directiva, compuesta por siete individuos, que eligieron como presidente de la nueva Asociación a Ramón de la Sota, auténtico impulsor de la entidad $^{19}$. A partir de ese momento las relaciones entre la Asociación de Navieros y la Liga Marítima pasaron del desencuentro inicial al entendimiento ulterior -visible claramente a partir de 1904-, toda vez que ambas instituciones compartieron siempre, entre otros objetivos, la demanda de concesión de primas a la construcción y a la navegación. Para evitar, precisamente, que la Asociación presidida por Sota transitase por una vía diferente a la Liga Marítima, en noviembre de 1903 el entonces Presidente de la Sección de Navegación de la Liga, el Marqués de Comillas, «puso a disposición de la Junta dicho cargo, renunciándolo en favor de quien asumiese la totalidad de la representación naviera, por ejercer la Presidencia de la nueva Asociación» ${ }^{20}$.

En el interím, los cambios el Consejo de Ministros habían aupado al mismo, en diciembre de 1902, tanto a Maura como a Sánchez de Toca, presidente y vicepresidente de la Liga. Acto seguido, ambos presentaron la dimisión de sus cargos en la Liga y fueron sustituidos, interina y respectivamente, por los marqueses de Reinosa y de Comillas ${ }^{21}$. Antes sus compañeros de la Junta se habían felicitado

${ }^{18}$ Valdaliso (1991, pp. 231-240)

19 El Economista no 912 (14-11-1903), p. 1252; Vida Maritima no 68 (20-11-1903), pp. 632-633. Sobre la creación de la Asociación General de Navieros véase también Torres (1998), especialmente pp. 175-181, así como el trabajo monográfico de Valdaliso (1990) sobre la Asociación de Navieros de Bilbao.

${ }^{20}$ Vida Maritima $\mathrm{n}^{\circ} 68$ (20-11-1903), pp. 630-631. Hubo asimismo sectores de las marinas militar y mercante que se organizaron corporativamente, si bien al margen de la Liga, como aquellos que se encuadraron en Fomento Naval, entidad presidida por Cristóbal Colón de la Cerda, Duque de Veragua y senador por derecho propio, que impulsó - a imagen y semejanza de la Liga Marítima- un Congreso Naval de escasas repercusiones en mayo de 1904. Vid. al respecto Vida Maritima $\mathrm{n}^{\circ} 64$ (10-10-1903), p. 555.

${ }^{21}$ Finalmente, tras su cese como Ministro de Marina, Sánchez de Toca pudo reincorporarse a la Junta Central de la Liga, sustituyendo entonces a Maura como Presidente. Para una biografía de este notable político véase González Ruiz (1948); vid. un breve resumen de su pensamiento político en Rueda Laffond (1993). 
públicamente por su incorporación al Gobierno, lo cual «permit[ía] asegurar que las gestiones de la patriótica Asociación, encaminados al cumplimiento de los acuerdos del Congreso marítimo y a la satisfacción de las aspiraciones justas de sus miembros, tendrán cada día resultados más completos y satisfactorios ${ }^{22}$. En efecto, en marzo de 1903 el Consejo de Ministros acordó declarar a la Liga asociación oficial y de utilidad pública, $y$, poco después, Joaquín Sánchez de Toca planteó con seriedad desde el Gobierno la necesidad de abordar la reconstrucción de la Escuadra española. Con Sánchez de Toca en el Ministerio de Marina no es de extrañar que la Liga dejase de efectuar propuestas propias para apoyar las del Ministro, especialmente aquellas que hacían referencia a la dotación de la Armada con nuevos barcos: «Del proyecto de ley de creación de [la] Escuadra [...] se estimó que no le correspondía a la Junta presentar texto, sino adherirse al de los dictámenes de la Junta de Escuadra, conforme con los acuerdos del Congreso Marítimo»». Para entonces, la Liga Marítima Española reunía más de 11.000 asociados, una cifra que, si bien no alcanzaba los 500.000 adheridos con que contaba entonces la poderosa Liga Naval alemana, superaba el número de afiliados de las ligas francesa e italiana y mostraba la incipiente capacidad de movilización de un proyecto nacido apenas quince meses antes ${ }^{23}$. La LME no dejó de crecer en los años ulteriores, llegando a contar en diciembre de 1910 con 39 juntas provinciales y locales y con más de 16.000 socios, entre individuales y colectivos ${ }^{24}$.

Al presentar el anteproyecto de presupuesto de Marina para 1904, Sánchez de Toca quiso afirmar que el aumento del gasto derivado de sus proyectos «por manera alguna compromet[ía] la política de severísima nivelación del presupuesto» y que, si bien «el programa de la escuadra [podía] resultar antitético de un presupuesto con política de nivelación meramente fiscal», se justificaba por el fomento de la riqueza nacional, que debía redundar en un futuro incremento de los ingresos del Estado ${ }^{25}$. No era de la misma opinión el Ministro de Hacienda, Raimundo Fernández Villaverde, quien dimitió en marzo de 1903 precisamente por las implicaciones pecuniarias de los planes de Sánchez de Toca, forzando de esa manera, como ha estudiado María Jesús González, la primera crisis del gabinete Silvela $^{26}$. En esa primera pugna fue Villaverde quien venció -al menos interinamente-, asumiendo, en julio, la presidencia del Gobierno y desplazando de sus

\footnotetext{
${ }^{22}$ Vida Maritima $\mathrm{n}^{\circ} 34$ (10-12-1902) y n 38 (20-1-1903), p. 31.

${ }^{23}$ El Mundo Naval Ilustrado $\mathrm{n}^{\circ} 37$ (20-1-1901), p. 20; Vida Maritima $\mathrm{n}^{\circ} 1$ (10-1-1902), p. 11 .

${ }^{24}$ Vida Maritima no 325 (10-1-1911), pp. 1-3; vid. también Navarrete (1917).

${ }_{25}$ Vida Maritima n ${ }^{\circ} 49$ (10-5-1903), pp. 242-244; véase también n ${ }^{\circ} 50$ (20-5-1903), pp. 269-270.

${ }^{26}$ González Hernández (1997, p. 52). Para un resumen de la labor hacendística de Fernández Villaverde véase Comín (1999); un análisis más extenso, en el número monográfico de Hacienda Pública Española, Villaverde en Hacienda, cien años después (1999).
} 
responsabilidades ministeriales tanto a Maura como a Sánchez de Toca. No obstante, meses después la caída del gabinete Villaverde confirmaba el liderazgo de Maura entre los conservadores: en diciembre de 1903 el político mallorquín asumía por primera vez la presidencia del Consejo, colocando a Sánchez de Toca como Ministro de Gracia y Justicia y a José Ferrándiz Niño, hasta entonces vocal de la Junta Central de la Liga, como Ministro de Marina.

Un mes antes, el 6 de noviembre de 1903, el entonces Ministro de Hacienda, Augusto González Besada, había presentado un primer Proyecto de Ley sobre Comunicaciones Marítimas, proyecto que, si bien respondía a la inquietud expresada con el nacimiento de la Liga y con el primer Congreso Marítimo, no era del completo agrado de sus dirigentes. A finales de mes, la Liga entregó sus propuestas a la correspondiente Comisión Parlamentaria, y unas semanas después se produjo la crisis de gabinete que aupó a Antonio Maura a la Presidencia del Consejo. Durante el verano de 1904 el mallorquín, primer presidente de la Liga Marítima, convenció a su Ministro de Hacienda, Guillermo de Osma, para modificar el texto, haciéndolo «entrar resueltamente por el camino de la protección [al menos] a la industria de construcciones navales», como recogía la prensa madrileña ${ }^{27}$. Finalmente, a principios de octubre de 1904, el gabinete presidido por Maura, «respondiendo a sus compromisos anteriores y a la confianza de cuantos en ellos [Maura, Sánchez de Toca, Rodríguez San Pedro, Osma, Ferrándiz] esperaban [...] ha[bía] ampliado el proyecto de ley de auxilios a la marina mercante presentado en la anterior legislatura por el Sr. González Besada en [...] conformidad con la mayor parte de las ideas predominantes en la Información de la Liga Marítima [...] la Liga puede estar por lo tanto satisfecha de la labor de sus miembros más distinguidos y de haber contribuido eficazmente a la obra de gobierno» ${ }^{28}$.

Apenas unos días después del dictamen final de la Comisión Parlamentaria, Maura presentaba su dimisión como Presidente del Consejo de Ministros. Su renuncia acabó con el optimismo de la Liga, al retardar inevitablemente sus aspiraciones. Ni para el gabinete presidido por Fernández Villaverde ni para los sucesivos gabinetes liberales la promulgación de una ley de protección a las industrias marítimas nacionales fue una prioridad, y menos en los términos impulsados por Maura. Además, la inestabilidad marcó la vida política parlamentaria: en los dieciocho meses que transcurrieron entre junio de 1905 y enero de 1907 se sucedieron hasta seis gabinetes liberales, con otros tantos ministros de Marina. En ese contexto, el segundo congreso de la Asociación General de Navieros Españoles,

\footnotetext{
${ }^{27}$ El Economista ${ }^{\circ} 958$ (1-10-1904), p. 1132. Sobre la labor de Osma al frente de Hacienda vid. Martorell (2000)

${ }^{28}$ Vida Maritima $\mathrm{n}^{\circ} 92$ (20-7-1904), p. 390; no 100 (10-10-1904), pp. 553-554; n 106 (10-12-1904), pp. 673-675. Sobre la insatisfacción de los navieros con el proyecto de González Besada, cfr. Arumí (1904) y Valdaliso (1990, p. 76).
} 
celebrado en Barcelona en noviembre de 1905, se vio forzado a exhortar, sin éxito, al Gabinete Montero Ríos en favor de «la inmediata discusión en las Cortes del proyecto de protección a la Marina mercante, que quedó sobre la Mesa del Congreso en las últimas Cortes» ${ }^{29}$. El 3 de febrero de 1906 el Gobierno presidido por Segismundo Moret abría un nuevo período de información extraparlamentaria, restringida sin embargo a las comunicaciones marítimas regulares. Hubo que esperar a que la nueva llegada al poder de Maura, en enero de 1907, acelerase el trámite de la Ley de Comunicaciones Marítimas hasta culminar con su aprobación. Maura, sin embargo, quiso antes hacer realidad otro proyecto largamente acariciado por la Liga, al que dio prioridad en su tramitación parlamentaria por delante del proyecto de ley que debía otorgar primas a la marina mercante: me refiero al programa para la reconstrucción de la escuadra.

\section{LA LEY DE LA ESCUADRA}

A mediados de 1907, José Ferrándiz Niño, Ministro de Marina de Maura, presentó un proyecto de ley cuya elaboración fue fruto de un largo proceso en el que había participado el propio Sánchez de Toca en su paso anterior por dicho ministerio, en $1903^{30}$. Años después de la pérdida de la mayor parte de la Armada española en Cavite y Santiago, el plan de Ferrándiz planteaba un programa relativamente ambicioso de reconstrucción de la escuadra de guerra; programa que, en coherencia con la previa Ley de Protección de las Industrias Nacionales (de 1907), se llevaría a cabo en los arsenales del país, que debían ser arrendados a una sociedad privada. Tras el correspondiente trámite parlamentario, la Ley de Organizaciones Marítimas y Armamentos Navales se aprobó el 7 de enero de 1908. Tres días más tarde, la Junta Central de la Liga Marítima, «congratulándose de que con ella se inicie la reconstitución del poder naval de España, a que la Liga ha dedicado desde su fundación todos sus esfuerzos», acordaba

«facilitar y estimular por los medios reglamentarios que pueda emplear todas las iniciativas individuales y colectivas encaminadas [...] a la agrupación de industrias nacionales y a que ellas ofrezcan al Gobierno con la asistencia extranjera que se estime necesaria los medios para que se realice con garantía de acierto la obra nacional iniciada $\rangle^{31}$

facultando para dicha labor a la Sección de armamentos y construcciones navales de la Liga, presidida por el Marqués de Comillas. El 5 de mayo de 1908 -es decir,

\footnotetext{
${ }^{29}$ El Economista $\mathrm{n}^{\circ} 1018$ (25-11-1905), p. 1348

${ }^{30}$ El Economista no 971 (31-12-1904), pp. 1489-1491, y no 995 (17-6-1905), pp. 674-675.

${ }^{31}$ Vida Maritima n $^{\circ} 217$ (10-1-1908), pp. 9-10.
} 
dos semanas después de que se publicase el Real Decreto que regulaba las condiciones de la licitación-, se convocó en la sede de la Liga Marítima una reunión bajo la presidencia de Sánchez de Toca en la cual se discutió «el modo de constituir una agrupación de fuerzas nacionales, económicas e industriales, suficientemente vigorosa para formar entidad nacional capaz de contribuir al éxito del concurso por el Gobierno convocado, previo consorcio con los más acreditados elementos extranjeros ${ }^{\prime 2}{ }^{32}$. Las empresas asistentes se dieron un corto plazo para estudiar el asunto y respondieron finalmente por escrito a la ponencia presentada por Joaquín Angoloti -vinculado a Altos Hornos de Vizcaya-, José María Cornet -Director de La Maquinista- e Ignacio Noriega: como no podía ser de otro modo, la Factoría Naval de Matagorda -propiedad de la Compañía Trasatlántica- «hizo presente su conformidad con las ideas sustentadas por la ponencia en su dictamen y manifestó estar dispuesta a contribuir oportunamente a la constitución de una entidad que realizase aquélla»; una respuesta similar dieron tanto Altos Hornos de Vizcaya -que manifestaba estar «completamente de acuerdo con los extremos de la ponencia y dispuesta á cooperar con las entidades que se resuelvan a plantear el asunto, constituyendo sociedad para ello»- como la Sociedad Anónima de Construcciones Mecánicas y Eléctricas de Barcelona.

En sentido opuesto se expresaron la Fábrica de Mieres, Astilleros del Nervión, Industria Eléctrica y el Sindicato Nacional, los cuales contestaban que «no podían prestar su conformidad a las bases generales del concurso», en la medida que dejaba la puerta abierta a la participación de firmas no españolas, mostrando así su disconformidad con la participación de Vickers y otras compañías británicas en la nueva entidad apadrinada por la Liga Marítima. En realidad, ese otro grupo industrial español, liderado por Jose Tartiere y que se separó de -o no pudo entrar en- la otra empresa promovida por la Liga, necesitó igualmente aliarse con sendas firmas constructoras británicas: Palmers Shipbuilding and Iron Co. Ltd., y William Beardmore and Co. Ltd. Paradójicamente, con el mismo lenguaje nacionalista de que había hecho gala la Liga Marítima, Tartiere y los suyos iniciaron una campaña pública denunciando que la iniciativa participada por Altos Hornos de Vizcaya y la Compañía Transatlántica encubría, en realidad, la cesión del programa naval a manos extranjeras. Sus argumentos contaron con el apoyo explícito del propio Sánchez de Toca, entonces directamente enfrentado a Antonio Maura y que encontró en la resolución del concurso una manera más de escenificar sus diferencias con el jefe de su partido. Por su polémica alianza con dichas firmas británicas, Sánchez de Toca acusó entonces a los empresarios españoles que impulsaron el nuevo proyecto -e implícitamente al propio Maura- de entrar «en el vasallaje de la plutocracia de Cosmópolis por la puerta de las mayores humillacio-

${ }^{32}$ Vida Maritima $\mathrm{n}^{\mathrm{o}} 237$ (30-7-1908), pp. 331-332; El Economista $\mathrm{n}^{\mathrm{o}} 1147$ (16-5-1908), p. 583 
nes $\rangle^{33}$. De cualquier forma, esa iniciativa -que acabó adoptando el nombre de Sociedad Española de Construcción Naval, o La Naval- suponía que dos grandes grupos de accionistas españoles - uno vasco, organizado en torno a Altos Hornos de Vizcaya, y otro catalán, articulado por los Comillas- se aliaban con destacadas firmas británicas del ramo de la construcción naval, como eran Vickers Sons \& Maxim Ltd., sir W. G. Armstrong Whitworth y John Brown \& Co. Ltd. ${ }^{34}$.

Finalmente, de los cuatro grupos que concursaron para hacerse con el programa de construcción de los buques de la Armada, fue la propuesta de La Naval la que acabó ganando la licitación. Esta sociedad parece haber sido un hijo más de la Liga Marítima, cuya sede social fue, como se ha visto, su sala de partos. No en vano el entonces vicepresidente de la Liga Marítima, Adolfo Navarrete, fue uno de los dos primeros gerentes de La Naval, mientras que el primer Presidente de la firma hispano-británica, Tomás de Zubiría, era asimismo vocal de la Junta Central de la Liga. Pronto se sucedieron las acusaciones de trato de favor por parte del Gobierno, y de que el proceso de adjudicación no había sido más que una farsa ${ }^{35}$. En este sentido, Bordejé añade además que «hubiera o no algo 'tras bastidores' [...] dicha sociedad [...] contaba de antemano con el beneplácito de sectores de la propia Armada $\rangle^{36}$. De cualquier forma, merced a la resolución del concurso, La Naval «se convirtió en el constructor militar del país», actividad por la que obtuvo pingües beneficios: en sus primeros diez años de existencia (1910-1919) los beneficios de la sociedad superaron los 15 millones de pesetas. No obstante, una parte de estas ganancias se debe a su vertiente como constructora de buques mercantes, labor a la que se incorporó en 1914. Así, la poderosa Transatlántica, presidida por el Marqués de Comillas, resultó singularmente beneficiada por esa opción de La Naval, que llevó aparejada la decisión de la firma hispano-británica de comprar los astilleros de la naviera catalana ubicados en Matagorda (Cádiz), hasta entonces fuente únicamente de problemas y de pérdidas para sus propietarios ${ }^{37}$.

\section{LA LEY DE FOMENTO DE LAS INDUSTRIAS Y COMUNICACIONES MARÍ- TIMAS NACIONALES}

Si la presentación del proyecto Ferrándiz-Maura de reconstrucción de la Escuadra tuvo lugar a mediados de 1907, fue asimismo en julio de ese año cuando el

\footnotetext{
${ }^{33}$ Ceballos Teresí (1908, p. 4). Para una descripción de los enfrentamientos entre Maura y Sánchez de Toca, véase González Hernández (1997, pp. 272-279).

${ }^{34}$ Lozano (1999). Vid. también El Economista no 1151 (13-6-1908), p. $702 ;$ n $^{\circ} 1152$ (206-1908), p. 730, y n 1185 (6-2-1909), pp. 166-167.

${ }_{35}$ Ceballos Teresí (1908), Harrison (1976, p. 120), Bordejé (1978, pp 182-183).

${ }^{36}$ Bordejé (1978, p. 165).

${ }^{37}$ Romero (1999). Sobre el sector de la construcción naval, véase también Houpt y OrtizVillajos (1998).
} 
Ministro de Fomento del gabinete presidido por Maura, González Besada, daba por acabados los trabajos de la comisión abierta por Gasset en relación al proyecto de ley de fomento de la marina mercante e industrias afines. A finales de enero de 1908, González Besada presentaba «el último proyecto de ley, sobre las bases del dictamen de la información extraparlamentaria de 1907. La Comisión parlamentaria dictaminó en 10 de julio de 1908» pasando después la discusión al Pleno $^{38}$. El propio Adolfo Navarrete pudo participar directamente en el debate de esta otra ley en su calidad de diputado al Congreso por el distrito de Tortosa, del que resultó elegido en abril de 1907 como candidato de la mayoría, es decir, adicto a Maura.

Navarrete actuó como secretario de una Comisión Parlamentaria presidida por Gabino Bugallal y compuesta, además, por Luis Redonet López-Dóriga, Manuel Argüelles, José Garay y Salvador Canals, encargada de estudiar y modificar el anteproyecto de Ley de Fomento de las Industrias y Comunicaciones Marítimas Nacionales presentado por el gobierno. La labor de la comisión debió ser intensa, en tanto que alteró sustancialmente el inicial proyecto que González Besada había presentado en su calidad de Ministro de Fomento, haciéndolo aun más proteccionista, como hizo notar en el Congreso el diputado liberal Juan Fernández Latorre. La réplica vino de parte de Manuel Argüelles, quien no pudo ser más explícito. Afirmaba el ponente que «entre el proyecto presentado por el señor González Besada y el dictamen de esta Comisión transcurrió un período de tiempo bastante largo, hubo una información parlamentaria y el Gobierno creyó oportuno cambiar la política económica que entonces seguía», es decir, pasar de un simple sistema de desgravaciones fiscales -o, en palabras de Argüelles, «sistema de protección indirecta»- a «un sistema de protección directa». Según rezaba el dictamen de la propia comisión, este cambio se había efectuado «de acuerdo con el Gobierno [modificándose] la protección que otorgaba éste en su proyecto de ley, en forma de desgravación de impuestos, por las primas a la navegación solicitadas». No fue el único cambio promovido por la Comisión Parlamentaria sino que, según el presidente de la misma, Gabino Bugallal, aunque «el proyecto [del Gobierno] excluía los tramps de las primas y de las bonificaciones [...] la Comisión ha incluido los tramps en las primas y en las bonificaciones». Además, se modificó el sistema de primas a la construcción a favor de los armadores por un nuevo sistema de primas que directamente favorecía a los constructores. Como decía Manuel Argüelles resumiendo el espíritu que había animado a los legisladores, «el problema de la construcción se reduce a términos muy sencillos: procurar a los astilleros

${ }^{38}$ Fundación Maura, Fondo Antonio Maura Montaner, legajo 404/1, carpeta 1. Véase una copia del Dictamen de la Comisión del Congreso de los Diputados en Vida Marítima n ${ }^{\circ} 236$ (20-7-1908), pp. 318-332; vid. también Diario de Sesiones de Cortes-Congreso [en adelante DSC-C], apéndice 17 al $\mathrm{n}^{\circ} 253$ (11-7-1908), pp. 1-20. 
nacionales la clientela del propio pabellón ${ }^{39}$. Sin duda, a Adolfo Navarrete le correspondió un lugar destacado en la tramitación, modificación y definitiva aprobación de la ley por la que tanto había trabajado la Liga Marítima: fue el miembro de la Comisión que tuvo una participación más activa en el trámite parlamentario, tomando la palabra en un total de veinticinco sesiones, y a él le correspondió recoger la única modificación propuesta por la oposición y aceptada por la ponencia en el marco del debate. Incluso se hizo cargo de la defensa de la obra legislativa de Maura en cuestiones marítimas en la sesión parlamentaria del 14 de noviembre de 1908 , en la que el político mallorquín estaba ausente, enlazando directamente la política de Maura con las propuestas de la Liga ${ }^{40}$.

El trámite parlamentario se alargó entre el 20 de octubre de 1908, cuando dieron inicio los debates, y el 25 de mayo de 1909, fecha en que se aprobó su redacción definitiva. Fueron muchos los diputados que tomaron la palabra, proponiendo 234 enmiendas, si bien no fueron tantos los que votaron finalmente en contra: apenas 33 diputados sobre un total de 219 votos emitidos, de los que los otros 186 fueron favorables. La lentitud en la tramitación de la ley exasperó a la Asociación General de Navieros Españoles que, en febrero de 1909, exhortó al parlamento para que cerrase la discusión y acabase por sancionar la ley ${ }^{41}$. Hubo, incluso, sectores de la opinión pública que apreciaban la mano de la naviera de Comillas, la poderosa Compañía Transatlántica, en cada uno de los avatares por los que iba pasando la tramitación de la ley. En diciembre de 1908, por ejemplo, la prensa económica de Madrid no dudaba en expresar su perplejidad:

«cuando no se discutía [en el Parlamento la Ley de Comunicaciones Marítimas] y estaba paralizada, se quejaban las oposiciones porque con la detención seguía cobrando la Transatlántica, que veía prolongado su contrato; ahora que el Gobierno quiere discutir aprisa esa ley [...] se quejan también. No lo entendemos. Lo natural y lógico era trabajar para que se modifiquen las condiciones del concurso para que no lo monopolice la Trasatlántica.»» ${ }^{42}$

\footnotetext{
${ }^{39}$ DSC-C n 27 (14-11-1908), p. 693 y ss; no 50 (14-12-1908), p. 1619 y ss; n 51 (15$12-1908)$, p. 1665 y ss; no 53 (17-12-1908), p. 1767 y ss.

${ }^{40}$ DSC-C no 27 (14-11-1908), p. 682 y ss.

41 Vida Marítima $\mathrm{n}^{\circ} 256$ (10-2-1909), pp. 58-59.

${ }^{42}$ El Economista $n^{\circ} 1178$ (19-12-1908), p. 1502. En el marco de la aprobación de la nueva Ley, véanse los argumentos de los partidarios de que la Transatlántica revalidase su contrato con el Estado en Vida Maritima $n^{\circ} 256$ (10-2-1909), pp. 51-52, y en Cuétara (1982, pp. 136-151). También las relaciones con la Transatlántica centraron la intervención de algunos parlamentarios, como Baldomero Vega de Seoane, quien se quejaba de la obsolescencia de la flota de dicha naviera y de que los informes a su favor los firmaban, en representación de diferentes entidades, individuos de la propia naviera; o como Rafael Gasset, especialmente duro con la Transatlántica, quien preguntó al hemiciclo: «¿Por qué, señores de la Comisión y Sr. Ministro de Fomento, no decir las cosas con entera claridad? ¿Por qué no decir que se trata [...] de dar una subvención de 10 millones a la Transatlántica?». Véase DSC-C n 26 (13-11-
} 
Los temores del redactor, sin embargo, se confirmaron y, aplicando la nueva Ley, la naviera de los Comillas volvió a revalidar sus privilegiadas relaciones con el Estado, prorrogando unas subvenciones que habían arrancado en 1861 y que se alargarían hasta el advenimiento de la Segunda República. Ahora bien, el establecimiento de los servicios regulares subvencionados por el Estado no agotaba el articulado de la dicha ley, que recogía además el espíritu -y la letra- de otras propuestas que la Liga Marítima Española había repetido significativamente en los años anteriores.

Tanto en la propuesta de la Comisión como en el redactado final de la Ley se acordó explícitamente reservar el comercio de cabotaje «exclusivamente para los buques de bandera y construcción nacionales» (art. $2^{\circ}$ ), así como el establecimiento de primas directas a la navegación para «los buques nacionales de vapor que [...] verifiquen tráfico directo internacional en navegaciones de altura y gran cabotaje» $\left(\right.$ art. $\left.6^{\circ}\right)$. De hecho, si el trabajo de la Comisión Parlamentaria había modificado el proyecto del Gobierno en un sentido todavía más proteccionista, el debate parlamentario había servido para, por un lado, incrementar levemente el grado de protección alcanzado y, por otro, suavizar el único punto perjudicial para los armadores, contenido en el artículo primero del proyecto. No en vano, las enmiendas incorporadas a la redacción final del texto permitieron introducir una serie de cambios, en su práctica totalidad favorables a los navieros ${ }^{43}$.

Inicialmente se había propuesto que las primas a la navegación a favor de los buques destinados a la navegación de altura fuesen de 0,30 pesetas por cada tonelada bruta y mil millas recorridas mientras que el trámite parlamentario permitió aumentar esa cifra en un 33 por 100, es decir, situarla en 0,40 pesetas por tonelada. Para la obtención de esas primas, el proyecto presentado por la Comisión establecía que los barcos debían acreditar que el promedio de su carga y pasaje en el último año no había sido inferior al 50 por cien de su capacidad total, mientras que una enmienda rebajó esa cifra al 40 por cien, aumentando así el número eventual de buques y armadores que podían acogerse a los beneficios de la Ley. Además, se añadió un nuevo párrafo al artículo 18 con la voluntad de favorecer el transporte de cabotaje de carbón español, merced al cual se acordaba instar al Gobierno para que presentase «a las Cortes, antes de un año, un proyecto de ley

1908), p. 649 y ss. y n 52 (16-12-1908), p. 1709 y ss. Vid. una ampliación del análisis de las relaciones entre la Transatlántica y el Estado español en Rodrigo (2000). Cabe señalar que, junto a la firma presidida por Comillas, entraron en el grupo de navieras que servían líneas regulares Navegación e Industria, Compañía Valenciana de Vapores-Correos de África, Isleña Marítima y Compañía Mahonesa de Vapores, empresas todas ellas que en 1916 se integraron en la Compañía Transmediterránea.

${ }^{43}$ Los diputados que actuaban como agentes parlamentarios en nómina del Círculo Minero de Bilbao consiguieron igualmente, en 1917, introducir enmiendas significativas que modificaron el Código Minero en su tramitación por el Senado. Véase al respecto Escudero (1990). 
especial; e interín sea aprobado [que] la exportación o distribución por el litoral en vía marítima del carbón nacional disfrutará de una prima de 0,30 pesetas por tonelada». Estas tres modificaciones obligaron asimismo a alterar el contenido de los artículos 11 y 12, que establecían el tope máximo a que podían ascender todas las primas a la navegación repartidas por el Gobierno: situado inicialmente en 4.750.000 pesetas, dicho límite subió ligeramente para colocarse finalmente en 4.900 .000 pesetas.

Había sido una aportación de la Comisión Parlamentaria incluir un primer epígrafe en el articulado de la Ley estableciendo un nuevo impuesto nacional al tráfico de altura, tasa que no se había planteado en el anteproyecto previo del Gobierno. La función de este nuevo impuesto era permitir al Estado aumentar sus ingresos ordinarios para poder financiar parcialmente el nuevo sistema de primas establecido en la Ley. Sectores de la vida económica del país reaccionaron pronto solicitando que no se aprobase dicho artículo: así, por ejemplo, las Cámaras de Comercio de Barcelona, Sevilla, Cartagena, Almería y Sant Feliu de Guíxols mandaron telegramas a las Cortes en demanda de su anulación. En su primera redacción, ese polémico artículo planteaba que «los buques de vapor nacionales y extranjeros satisfarán en el primer puerto español donde efectúen operaciones [...] un impuesto de una peseta por cada tonelada neta de registro». Este impuesto debía suponer al Gobierno -según cálculos propios de la Comisión Dictaminadoraun incremento en sus ingresos no inferior a 1.750 .000 pesetas. En cierta medida, esa nueva tasa debía permitir que las firmas navieras extranjeras que tocaban en los puertos españoles financiasen las primas de sus competidoras españolas, pero penalizaba igualmente a los armadores del país. Finalmente, una enmienda hizo disminuir el impuesto hasta situarlo en 0,75 pesetas por cada tonelada de registro neto -es decir, redujo en un 25 por 100 la presión fiscal prevista-, estableciéndose algunos supuestos en que la tasa disminuía hasta las 0,50 pesetas por tonelada. No satisfechos con ese cambio, añadieron dos párrafos al artículo 19 que contemplaban la exención o reducción de dicho impuesto para buques que, procediendo de un puerto español y tras un viaje redondo, transportasen a su vuelta a España cualquier producto incluido en una lista de más de veintinueve mercancías, entre las cuales se incluían algodón y tabaco en rama, cueros y pieles sin curtir, café o té, por citar algunas.

Además, la aprobación de dicha Ley permitió el establecimiento de un sistema de primas también para los astilleros españoles. Su título segundo

«arbitraba un sistema de protección directa basado en primas a la producción nacional que oscilaba entre las 80 y las 185 pesetas por tonelada. Este sistema recogía con amplitud el anterior nivel de protección por primas y los derechos arancelarios satisfechos por los constructores. De esa manera, a la vez que se contentaba a los siderúrgicos con el mantenimiento de 
los derechos de importación, se devolvía a los constructores, a través de una prima mayor, los impuestos de aduana pagados. $\rangle^{44}$

A la par -y tras la adjudicación del concurso de construcción de la nueva Escuadra-, en agosto de 1909 se constituyó en Madrid la Asociación de Constructores Navales Nacionales, en el mismo domicilio que la Liga Marítima, «de la que se considerará filial para todos los efectos», dedicada a «gestionar ante los poderes públicos cuantas resoluciones o medidas sean conducentes» a la protección de los astilleros españoles. Su primer presidente fue, por supuesto, el Marqués de Comillas, su secretario era Adolfo Navarrete, y, de los cuatro vocales, dos eran Consejeros de La Naval: Ignacio Noriega y el conde de Zubiría. Pudo entonces tomar forma un acuerdo de la Junta Central de la Liga adoptado cuatro años antes, en mayo de 1905, fecha en que había decidido «favorecer la Asociación de constructores navales para que su industria se coloque en condiciones de representación y defensa colectiva análogas a otras industrias, como la hullera, siderúrgica, naviera, pesquera, etc. representadas en la Liga ${ }^{45}$. No fue ésa la única sociedad filial de la Liga Marítima, sino que hubo otras: algunas de gran relevancia, como la Hullera Nacional, constituida en 1905 para presionar a favor de una protección efectiva a la producción española de carbón.

\section{LA HULLERA NACIONAL}

Los esfuerzos del segundo marqués de Comillas para constituir un grupo de presión dedicado a solicitar protección en beneficio del carbón nacional arrancan, cuando menos, de enero de 1891, fecha en que impulsó la creación de la Liga General de los Intereses Hulleros de España. Dicha entidad nació al calor de la discusión del nuevo arancel y -a pesar de que sólo recogió apoyos en Asturias pero no en el resto de España- fue capaz de conseguir al poco de su nacimiento un pequeño aumento de derechos que estimuló la minería en los años siguientes. De hecho, las presiones de determinados empresarios mineros -singularmente, como ha señalado Ignacio Arana, del marqués de Comillas- consiguieron un incremento de la protección al carbón nacional, expresada en un aumento del arancel, que pasó de 1,25 pesetas por cada $1.000 \mathrm{kgs}$. en 1891 a $2,50 \mathrm{pts}$. en 1892 y a 3,50 pts. en $1895^{46}$. A partir de esa última fecha, ni las gestiones de la la Liga General de los

\footnotetext{
${ }^{44}$ Romero (1999, p. 257).

${ }_{45}$ El Economista ${ }^{\circ} 1121$ (7-8-1909), pp. 946-947; Vida Maritima $\mathrm{n}^{\circ} 123$ (30-5-1905), p. 291

${ }^{46}$ Arana (1988, pp. 79-80, 247 y 558). Sobre la prórroga del recargo a los derechos arancelarios del carbón extranjero aprobado en la Ley de Presupuestos de 1895-96 hasta la aprobación del Arancel Villaverde, véase Sabaté (1996, pp. 53-55).
} 
Intereses Hulleros ni de la Unión Minera de España, constituida en 1898, consiguieron modificar la política impositiva y arancelaria de Villaverde, quien redujo los aranceles al carbón extranjero. En esa situación, el Marqués de Comillas creyó que era conveniente canalizar sus acciones de presión en favor de la hulla española a través de la Asociación Hullera Nacional, cuyos primeros pasos datan del otoño de 1904 y cuya constitución formal tuvo lugar en $1905^{47}$.

La agenda de las empresas hulleras estaba marcada entonces por la discusión de un nuevo arancel -aprobado finalmente en marzo de 1906- que acabó recogiendo buena parte de las demandas expresadas por la Hullera Nacional. De hecho, el Arancel Salvador de 1906 no sólo no disminuyó sino que aumentó la protección efectiva al carbón nacional: si, en términos nominales, las 2,50 pesetas/ tonelada del arancel Villaverde se situaron en 3,50 y 4 pesetas/tonelada para el carbón y el cock/aglomerados, respectivamente, en términos reales, con el nuevo arancel de 1906, la protección del sector pasó del 7,05 por cien en 1900-1903 al 14,4 por cien en 1907-1910. De hecho, el nuevo arancel se situaba sólo un poco por debajo de las demandas de la Liga Hullera expresadas en octubre de 1904. Además, como señalaron Rafael Anes y Germán Ojeda «la ley de 1906 [...] abr[ió] el paso a sucesivas disposiciones; [...] desde 1906 a 1914 es cuando se inició fundamentalmente la protección al carbón nacional $\rangle^{48}$. En ese sentido cabe entender, por ejemplo, las subvenciones de 0,30 pesetas por tonelada y mil millas establecidas en la Ley de Comunicaciones Marítimas de 1909 en favor de los navieros que transportasen carbón español por el litoral peninsular.

En el plano cronológico, el aumento de la protección efectiva a la hulla del país sancionado por el Arancel Salvador fue el primer éxito notable conseguido por la Liga Marítima, a los seis años de su fundación. Meses más tarde se aprobó la Ley de la Escuadra y, aún después, en el verano de 1909, la Ley de Fomento de las Industrias y Comunicaciones Marítimas Nacionales. A partir de ese momento, la LME se centró básicamente en participar en diferentes organismos públicos en los que tenía

«representación autorizada [como] en el Consejo Superior de Emigración, en el Consejo Superior y en los provinciales de Fomento; en el Consultivo de Navegación y Pesca Marítima; en la Junta Consultiva de Comunicaciones e Industrias Marítimas; en la Comisión de Información Hullera; en las Juntas de Obras de Puertos y en otros organismos nacionales creados recientemente para la reglamentación de leyes marítimas y su cumplimiento ${ }^{49}$.

${ }^{47}$ Vida Marítima $\mathrm{n}^{\mathrm{o}} 101$ (20-10-1904), p. 577; Manual de la Liga ..., especialmente, cap. V. Informaciones de la Unión Minera de España en Torres (1998). A partir de 1905, Adolfo Navarrete -secretario tanto de la LME como de la Liga Hullera- incorporó a su acción propagandista la demanda de mayor protección para la hulla española. Cfr. Navarrete (1909).

${ }_{48}$ Anes y Ojeda (1981). García Delgado, Roldán, y Muñoz (1973, pp. 102-111) habían señalado asimismo el notable papel que tuvo la Liga en este proceso.

${ }^{49}$ Vida Maritima $\mathrm{n}^{\mathrm{O}} 325$ (10-1-1911), pp. 1-3. 
Los diferentes intereses empresariales articulados en torno a la Liga Marítima supieron utilizar esos canales para participar en comisiones con atribuciones políticas; así, por ejemplo, prácticamente todos los miembros de la Comisión establecida en julio de 1909 por el Ministerio de Fomento para la redacción del Reglamento que desarrollase la Ley de Comunicaciones Marítimas participaban de la vida de la Liga Marítima $^{50}$. En cierta manera, la existencia y funcionalidad de ese tipo de comisiones, que permitían vehicular la representación de intereses en el seno de organismos emanados de las instituciones del Estado, pudo ayudar a prefigurar el camino hacia la corporativización de la vida política que acompañó a la crisis política de la Restauración, dos lustros después del fin del período que aquí analizamos ${ }^{51}$.

Al tomar parte en esos organismos consultivos, los empresarios participantes de la Liga Marítima se aseguraron de que los beneficios obtenidos merced a la legislación proteccionista se mantuviesen durante años. Un buen ejemplo lo tenemos en las primas a la navegación, un instrumento supuestamente concebido para contrarrestar momentos de crisis que se mantuvo en los años de bonanza del sector, mejorando la cuenta de resultados de las navieras españolas e incrementando de forma notable sus ganancias. En el caso de la Compañía Marítima del Nervión, por ejemplo, las ayudas estatales oscilaron entre el 106,4 por cien de sus beneficios después de impuestos en 1910 y el 31,1 por cien en 1913. Tras el paréntesis abierto por la Gran Guerra -en el que muchos armadores renunciaron voluntariamente al cobro de dichas primas a cambio de no sujetarse a otros aspectos de la Ley- un decreto del Directorio de Primo de Rivera restableció en 1925 la vigencia de las mismas, aumentando incluso su cuantía. Entre 1926 y 1930 las primas recibidas por la Naviera Sota y Aznar representaron el 43 por cien de sus beneficios líquidos -incluidas las amortizaciones- y el 45 por cien de los beneficios líquidos de la Naviera Vascongada entre 1926 y 1935. La Compañía Marítima del Nervión, por su parte, recibió un total de 2,2 millones de pesetas en 1927 y 1931-1933, que significaron el 60 por cien de sus beneficios después de impuestos en esos años. Para la Casa Hijo de Ramón A. Ramos, de Barcelona, cuyo gerente era el diputado maurista Ricardo Ramos Cordero, las primas recibidas llegaron a representar hasta un 25 por cien del beneficio líquido comercial de algún ejercicio, como el de $1928^{52}$.

\section{6. ¿FUERON LAS GESTIONES DE LA LIGA DETERMINANTES EN LA CONFI- GURACIÓN DEL PROTECCIONISMO ALAS INDUSTRIAS MARÍTIMAS?}

A la luz del análisis ofrecido en las páginas anteriores parece razonable dar a la pregunta una respuesta positiva. El éxito aparece como la culminación de los

\footnotetext{
${ }^{50}$ El Economista $\mathrm{n}^{\circ} 1207$ (10-7-1909), p. 829.

${ }^{51}$ Del Rey (1986).

52 Valdaliso (1991, p. 200) y (1993, pp. 35-42), Rodrigo (2003).
} 
esfuerzos, demandas, campañas de propaganda y estrategias parlamentarias de la Liga Marítima Española. Un éxito que tardó, ciertamente, varios años en formalizarse y que tuvo que esperar, en buena medida, al gobierno largo de Maura para hacerse efectivo. No parece de recibo, sin embargo, sugerir que el político mallorquín actuase, simplemente, como un agente de la Liga; al contrario, para entender la simbiosis entre la obra legislativa de Maura y las demandas proteccionistas canalizadas por la Liga Marítima me parecen más sugerentes conceptos como la correspondencia de intereses entre clase empresarial y clase política, de la que habla J.M. Valdaliso al analizar las estrategias de presión de los navieros bilbaínos $^{53}$. Aunque Maura se despegó expresamente de la cabeza de la Liga Marítima ya a mediados de noviembre de 1903, es decir, pocas semanas antes de asumir por primera vez la Presidencia del Gobierno -alcanzando así la jefatura de las filas conservadoras-, no es menos cierto que a partir de entonces no sólo atendió las peticiones de la Liga sino que dejó que la entidad -y singularmente Adolfo Navarrete- utilizase constantemente su nombre como fuente de autoridad, citándole como el principal inspirador de las gestiones de la Liga en foros tales como el parlamento o, posteriormente, en los círculos propiamente mauristas ${ }^{54}$. Ahora bien, Antonio Maura quiso y supo asimismo servirse de las labores de la Liga Marítima para hacer avanzar sus propuestas en materia de política naval, que era, como ya señalé, una de sus primarias preocupaciones políticas. Y todo indica que fue el político mallorquín quién, en última instancia, determinó el calendario que permitió tomar cuerpo a las peticiones proteccionistas, haciendo que los hombres de la Liga se sometieran a las dinámicas propias de la vida parlamentaria, y no al revés. En ese sentido, podemos apreciar también aquí una instrumentación recíproca entre intereses económicos y políticos, en el sentido que sugirió en su día Fernando del Rey ${ }^{55}$.

Como es sabido, la coyuntura en la que los hombres de la Liga Marítima demandaron -y consiguieron- ayudas públicas para los diferentes sectores de la economía marítima se caracterizaba por un auge de las peticiones proteccionistas no sólo en el Estado español sino también en el conjunto de Europa. En el caso de España, recientes investigaciones apuntan que determinados sectores -como

\footnotetext{
53 Valdaliso (1990).

${ }^{54}$ Vida Marítima $\mathrm{n}^{\circ} 68$ (20-11-1903), pp. 630-631. Adolfo Navarrete intervino en diferentes actos organizados por los círculos mauristas -por ejemplo, el 13 de abril de 1915 a instancias de la Juventud Maurista de Madrid o el 25 de noviembre de 1916 invitado por los mauristas de Bilbao- reivindicando siempre el nombre de Maura como inspirador de la política de la Liga. Véase al respecto Navarrete (1917). Cabe señalar que, profesionalmente, el político y abogado mallorquín trabajó para navieras como la Compañía Transatlántica. Al respecto, Fundación Maura, Fondo Antonio Maura Montaner, legajo 45, carpeta 2, carta de J. Gil Becerril a Antonio Maura, de 23 de marzo de 1915.

${ }^{55}$ Del Rey (1986 y 1992). Para una visión del político Antonio Maura desde su actividad inversora, véase Rueda (1991).
} 
la burguesía agro-exportadora valenciana- a los que se había atribuido un papel librecambista se vieron igualmente envueltos en esa vorágine petitoria en demanda de políticas que consiguiesen la reserva del mercado nacional para aquellas mercancías que difícilmente podían competir en otros países ${ }^{56}$. A mi entender, la habilidad en esa etapa de la Restauración de cada uno de esos grupos de presión, como la Liga Marítima, para conseguir que sus demandas tomasen cuerpo normativo - unas demandas que solían entrar en conflicto con los exhortos de otros grupos de intereses igualmente organizados- estuvo condicionada por su capacidad de establecer -o no- vínculos de conexión más o menos directa tanto con el poder legislativo como con el ejecutivo.

En el caso que nos ocupa, la llegada al poder de Antonio Maura, primer presidente de la Liga, significó para la entidad una apertura de las puertas del gabinete a sus demandas. La elección de Adolfo Navarrete, incansable portavoz de la Liga Marítima, como diputado por Tortosa sin ningún tipo de vinculación -ni arraigo- con ella, para tomar asiento en el Parlamento precisamente en la legislatura en que se acabó de debatir el Proyecto de Ley de Fomento, tuvo la única finalidad de dar voz directa en el Congreso a la Liga Marítima. Valga añadir que, agotada esa legislatura, Navarrete abandonó su escaño para seguir ejerciendo como secretario de la Liga y como gerente de La Naval. En las Cortes, la función de Navarrete -y posiblemente la de otros diputados de la mayoría- fue conseguir una especie de lobby parlamentario afín a las tesis de la Liga. De hecho, a pesar de que el reglamento del Congreso de la Restauración no contemplaba la existencia de grupos parlamentarios, $\mathrm{y}$ de que los diputados se agrupaban únicamente en heterogéneas secciones -en las que participaban políticos de adscripciones diferentes-, no resulta difícil encontrar referencias de grupos parlamentarios que englobaban a los diputados -y senadores- que compartían una determinada afinidad, una misma preocupación por un tema en concreto, y que podían actuar como portavoces de esos intereses. Así, por ejemplo, el órgano de prensa de la Liga Marítima daba noticia en 1910 de las gestiones de «los diputados y senadores que forman el grupo parlamentario africanista», los cuales habían «dirigido a sus compañeros de ambas Cámaras una circular recabando su adhesión, en la cual se elogia la constante labor de los Centros hispano-marroquíes en pro de los intereses económicos y políticos de España en África ${ }^{57}$. En su reciente análisis de la vida parlamentaria de la Restauración, Miguel Martorell ha afirmado que «muchos diputados y senadores eran lobbyst de grandes empresas [y que] los dirigentes de las principales organizaciones patronales agrarias, industriales o mercantiles solían tener reservado un escaño en cualquiera de las dos Cámaras» ${ }^{58}$.

\footnotetext{
${ }^{56}$ Garrido (2000)

${ }^{57}$ Vida Marítima $\mathrm{n}^{\circ} 309$ (30-7-1910), p. 334

${ }^{58}$ Martorell (2000, p. 30).
} 
El entonces principal periódico económico y financiero del país, El Economista -publicación que se autodefinía como «periódico de los ricos» y que afirmaba que «la defensa de los capitalistas [era su] lema ${ }^{59}$ - publicó en los primeros meses de 1909 una extensa nota sobre los políticos consejeros de sociedades con reflexiones interesantes sobre las relaciones entre la vida parlamentaria y el mundo empresarial. El redactor afirmaba entonces que

«la presencia de hombres políticos en los consejos [de las empresas] puede favorecer los intereses de la sociedad [...] por esto y para esto suelen buscarse, escogiéndolos de los partidos turnantes en el poder, personajes para algunos de esos altos puestos en los consejos de administración. Negarlo, sería discutir de mala fe [...] se buscan [...] hombres políticos influyentes, de empuje» ${ }^{60}$

de los que se conseguía una especie de «prestigio alquilado, una influencia tomada a sueldo cotizando con éste sólo aquellos futuros favores que podrá arrancar a los Gobiernos u obtener en las Cortes como jefe de grupo o ministro» ${ }^{61}$. La justificación parecía clara: «el mal está en que la justicia y el derecho son a veces francamente atropellados y otras soslayados por las influencias personales». Por último, el redactor culminaba afirmando «que si hay hombres que van desde la política a los Consejos de las Sociedades, no faltan algunos que van desde los Consejos a la política ${ }^{62}$. Las vinculaciones entre políticos y empresarios eran tan estrechas que conceptos como clase política o autonomía de la política tienen poco sentido para el análisis de la Restauración, una etapa en la historia de España en la que el ámbito del poder se mostró especialmente permeable a los juegos de influencias.

Sirviéndome del afortunado título del libro compilado por Antonio Robles Egea, diría que las influencias de esos grupos de presión y su capacidad para condicionar el marco legislativo y su posterior aplicación ofrecen, junto al caciquismo y al clientelismo, una de esas penumbras de la política características de la España contemporánea $^{63}$. Como ha sucedido con los estudios que han alumbrado un mejor conocimiento del clientelismo político, es cometido de economistas, historiadores y politólogos sacar a la luz las influencias -o limitaciones, en su caso- de los grupos de presión en el juego político. Fruto de ese esfuerzo debe entenderse este trabajo sobre la Liga Marítima en el marco de la Restauración, un período

\footnotetext{
${ }^{59}$ El Economista ${ }^{\circ} 1181$ (2-1-1909), p. 4

${ }^{60}$ El Economista n ${ }^{\circ} 1187$ (20-2-1909), p. 213

61 Ibidem, p. 214.

${ }^{62}$ Ibidem, p. 215.

${ }^{63}$ Robles Egea (1996), Moreno Luzón (1995).
} 
cuya crisis final acabó modificando sustancialmente dichas reglas de juego, también para las formas de ejercer presión por parte de los grupos de interés ${ }^{64}$. Está claro que en una dictadura como la de Primo de Rivera los cambios en la concepción y en el ejercicio del poder político modificaron radicalmente el escenario, así como las vías de comunicación entre intereses económicos y decisiones políti$\operatorname{cas}^{65}$. Posiblemente este hecho ayuda a explicar por qué con la crisis y el fin ulterior de la Restauración la vida de la Liga Marítima y de sus entidades filiales deviniese lánguida y su capacidad de presión prácticamente nula, escenario que no se modificó con el advenimiento de la Segunda República. El asesinato del Secretario General de la Liga, el capitán de navío retirado Pedro María Cardona, en agosto de 1936 es una metáfora -violenta, si se quiere- del fin de la entidad. En 1939, al finalizar la Guerra Civil, el anterior Vice-secretario, Luis Rodríguez Pascal, intentó reflotar la entidad con la sola ayuda del Capitán de Fragata Juan Navarro Dagnino. No obstante, en palabras del propio Navarro, «no fue posible reorganizar la Liga, y muerto don Luis [Rodríguez Pascal] el jueves Santo del año 1942, al quedar yo solo, y después de consultar con elevadas personalidades, procedí al abandono del local social en donde radicó la Liga más de treinta años $\rangle^{66}$, en la madrileña calle Zurbano, número 8. Acababa entonces una historia iniciada cuarenta y tres años antes, en 1899.

\section{FUENTES}

Archivo de la Fundación Antonio Maura (Madrid). Fondo Antonio Maura Montaner, legajos 45 y 404 .

\section{BIBLIOGRAFÍA}

Anes, R. y OjedA, G. (1981): «La minería del carbón en Asturias y los problemas del transporte en las primeras décadas del siglo XX». Hacienda Pública Española 69, pp. 303313.

Arana Pérez, I. (1988): La Liga Vizcaina de Productores y la política económica de la Restauración, 1894-1914. Bilbao: Caja de Ahorros Vizcaína.

ARumí SAURí, J. (1904): Marina mercante española. Decadencia actual y proyecto para su protección y fomento. Barcelona: A. López Robert.

\footnotetext{
${ }^{64}$ Del Rey (1986 y 1992).

${ }^{65}$ Dos análisis imprescindibles para el período son los de Ben-Ami (1984) y Gómez Navarro (1991). En su estudio de caso, Escudero (1990) aprecia cómo el potente lobby minero de 1886-1920 pasó a ser totalmente inoperante con la Dictadura

${ }^{66}$ Navarro Dagnino (1944, p. 769).
} 
Ben-Ami, S. (1984): La dictadura de Primo de Rivera (1923-1930). Barcelona: Planeta.

Bordeje y Morencos, F. de (1978): Vicisitudes de una política naval. Madrid: San Martín.

CABrera, M. (1983): La patronal ante la II República. Organizaciones y estrategia, 19311936. Madrid: Siglo XXI.

- (1997): «La modernización política. Los empresarios en la Historia de España». Papeles de Economía Española 73, pp. 272-284.

- (dir.) (1998): Con luz y taquígrafos. El Parlamento en la Restauración (1913-1923). Madrid: Taurus.

Cabrera, M. y del Rey, F. (2002): El Poder de los empresarios. Política y economía en la España contemporánea (1875-2000). Madrid: Taurus.

CAwson, A. (1986): Corporatism and Political Theory. Londres: Basil Blackwell

Ceballos Teresí, J. G. (1908): La nacionalización del poder naval y el concurso para la Escuadra. Madrid.

Comin, F. (1999): «La reforma en la Hacienda de Fernández Villaverde» en P. Tedde (ed.), Economía y colonias en la España del 98. Madrid: Síntesis, pp. 235-260.

Cubel, A. (1994): «Los efectos del gasto del Estado en la industria de construcción naval militar en España, 1887-1936», Revista de Historia Industrial 5, pp. 93-118.

CuÉtara Martinez, J. M. de la (1982): Las comunicaciones maritimas en España. La Laguna: Universidad

Del Rey Reguillo, F. (1986): «La crisis de una sociedad: el protagonismo de los poderes económicos»», en J.L. García Delgado (ed.), La crisis de la Restauración: España, entre la Primera Guerra Mundial y la Segunda República. Madrid: Siglo XXI, pp. 22-50.

- (1992): Propietarios y patronos. La politica de las organizaciones económicas en la España de la Restauración (1914-1923). Madrid: Ministerio de Trabajo y Seguridad Social.

Diario de Sesiones de Cortes. Congreso. Legislatura de 1908-1909. Madrid.

Economista, El (1903 a 1905 y 1908-1909).

Escudero, A. (1990): «El ‘lobby’ minero vizcaíno». Historia Social 7, pp. 39-68.

Exposición presentada al Excmo. Sr. Presidente del Consejo de Ministros por el Comité Central de la Liga General de los Intereses Hulleros de España (1896). Madrid.

Fraile Balbín, P. (1991): Industrialización y grupos de presión. La economía política de la protección en España, 1900-1950. Madrid: Alianza.

García Delgado, J. L., Roldán, S. y Muñoz, J. (1973): La formación de la sociedad capitalista en España. Madrid: CECA.

GARRIDO, S. (2000): «Realment eren lliurecanvistes? Les peticions aranzelàries de l'agrarisme valencià al començament del segle XX». Afers 36, pp. 379-396.

Gómez Navarro, J. L. (1991): El régimen de Primo de Rivera. Madrid: Cátedra.

González Hernández, M. J. (1997): El universo conservador de Antonio Maura. Biografia y proyecto de Estado. Madrid: Biblioteca Nueva.

González Ruiz, N. (1948): Sánchez de Toca. Madrid: Editorial Purcalla.

Harrison, J. (1976): «El coste de oportunidad del Programa Naval español de 1907: ¿pantanos o acorazados?». Hacienda Pública Española 38, pp. 111-122.

Houpt, S. y Ortiz Villajos, J. M. (1998): Astilleros españoles, 1872-1998. La construcción naval en España. Madrid: Lid.

Información de la Liga Maritima Española sobre protección a las industrias marítimas nacionales. (1903): Madrid. 
Lozano Courtier, A. (1999): "'A Source of Modest Comfort': Las inversiones de Vickers en España, 1897-1936». Revista de Historia Industrial 16, pp. 69-90.

Manual de la Liga Marítima Española. Cinco años de labor, 1900-1905. (1906): Madrid.

Martorell Linares, M. (2000): El santo temor al déficit. Política y hacienda en la Restauración. Madrid: Alianza.

Meny, I. y Thoenig, J. C. (1992): Las politicas públicas. Barcelona: Ariel.

Moldes Teo, E. (1987): Elección pública: hacia una teoría de los fallos colectivos. Madrid: Instituto de Estudios Fiscales.

Moreno Luzón, J. (1995): «Teoría del clientelismo y estudio de la política caciquil». Revista de Estudios Politicos 89, pp. 191-224.

- (1998): Romanones. Caciquismo y politica liberal. Madrid: Alianza.

Mundo Naval Ilustrado, El (1901).

NADAL, J. y SudRiÀ, C. (1993): «La controversia en torno al atraso económico español en la segunda mitad del siglo XIX (1860-1913)». Revista de Historia Industrial 3, pp. 199-227.

Navarrete, A. (1909): El carbón nacional y su transporte. Madrid.

- (1917): El problema marítimo de España. Madrid.

Navarro Dagnino, J. (1944) «La Liga Marítima. In Memoriam». Revista General de Marina (junio), pp. 765-769.

Olson, M. (1992): La lógica de la acción colectiva. Bienes públicos y la teoría de grupos. México: Noriega editores.

Pan-Mantojo, J. (1998): «El atraso económico y la regeneración», en J. Pan-Montojo (coord.), Más se perdió en Cuba. España, 1898 y la crisis de fin de siglo. Madrid, Alianza, pp. 261-334.

Pan-Mantojo, J. y Puig Raposo, N. (1995): «Los grupos de interés y la regulación pública del mercado de alcoholes en España (1887-1936)». Revista de Historia Económica 13 (2), pp. 251-280

PAstor Prieto, S. (1982): El transporte marítimo en España: crecimiento, crisis y politica económica. Bases para una ordenación económica del sector. Madrid: Servicio de Repografía de la Universidad Complutense, 2 vols.

Pelechá Zozaya, F. (1987): El proteccionismo industrial en España (1914-1931). Barcelona: PPU.

Revista General de Marina (1899-1912 y 1944).

Robles Egea, A. (comp.) (1996): Politica en penumbra. Patronazgo y clientelismo politicos en la España contemporánea. Madrid: Siglo XXI.

Rodrigo y Alharilla, M. (2000): Los marqueses de Comillas, 1817-1925. Antonio y Claudio López. Madrid: LID.

- (2003): La Casa Ramos, 1845-1960. Más de un siglo de historia marítima. Ejemplar mimeografiado, finalista del IV Premi de Recerca Josep Ricart i Giralt.

- (2004): «Estrategias de presión de los armadores catalanes: la Asociación de Navieros y Consignatarios de Barcelona», en VV.AA., Josep Fontana, història i projecte social. Reconeixement a una trajectòria Barcelona, Crítica, vol. 2, pp. 1127-1139.

Romero GonzÁlez, J. (1998): «El astillero gaditano de la Transatlántica: un caso de inversión industrial catalana en Andalucía», en VV.AA., Catalunya y Andalucía en el siglo $X I X$. Cornellà: Fundació Gresol, pp. 127-139. 
- (1999): Matagorda, 1870-1940. La construcción naval española contemporánea. Cádiz: Universidad de Cádiz-Astilleros Españoles.

Rueda LAFFond, J. C. (1991): «Antonio Maura: las pautas inversionistas de un miembro de la elite política de la Restauración». Historia Social 11, pp. 125-144.

- (1993): «Conservadurismo político y nacionalización económica. Una aproximación al pensamiento político de Joaquín Sánchez de Toca», en J. Tusell, J. Gil Pecharromán y F. Montero (eds.) (1993), Estudios sobre la derecha española contemporánea. Madrid: UNED, pp. 147-160.

SAbaté Sort, M. (1996): El proteccionismo legitimado. Política arancelaria española a comienzos de siglo. Madrid: Civitas.

SÁnchez de Toca, J. (1898): Del poder naval en España y su política económica para la nacionalidad Ibero-Americana. Madrid: Imprenta de los Hijos de M.G. Fernández.

- (1900): Las reformas en Marina. Madrid.

- (1903): Nuestra defensa naval, primer programa. Madrid: Imprenta de El Correo.

Serrano Sanz, J. M. (1987): El viraje proteccionista en la Restauración. La politica comercial española, 1875-1895. Madrid: Siglo XXI

Sierra Alonso, M. (1996): La política del pacto. El sistema de la Restauración a través del partido conservador sevillano (1874-1923). Sevilla: Diputación de Sevilla.

Tomás CARPi, J. A. (1985): «La teoría económica de la toma de decisiones políticas y la teoría del Estado: alcance y límites del discurso del Public Choice». Hacienda Pública Española 93, pp. 133-167.

Torres Villanueva, E. (1998): Ramon de la Sota, 1857-1936. Un empresario vasco. Madrid: Lid.

TuÑón de LaRa, M. (1971): Estudios sobre el siglo XIX español. Madrid: Siglo XXI.

VAldaliso GaGo, J. M. (1990): «Política económica y grupos de presión: la acción colectiva de la Asociación de Navieros de Bilbao, 1900-1936». Historia Social 7, pp. 69103.

- (1991): Los navieros vascos y la marina mercante en España, 1860-1935. Una historia económica. Bilbao: Instituto Vasco de Administración Pública.

- (1993): Desarrollo y declive de la flota mercante española en el siglo XX: la Compañía Marítima del Nervión (1907-1986). Madrid: Fundación Empresa Pública-Programa de Historia Económica, Documento de Trabajo 9305.

Valdaliso Gago, J. M. y López Losa, E. (2001): «Las 'Cenicientas' de la historia económica española: la historiografía económica sobre las industrias marítimas desde finales del siglo XIX hasta la actualidad», en A. Di Vittorio y C. Barciela (eds.), La storiografia marittima in Italia e in Spagna in età moderna e contemporanea. Bari: Cacucci Editore, pp. 427-450.

Varela Ortega, J. (1977): Los amigos politicos. Partidos, elecciones y caciquismo en la Restauración (1875-1900). Madrid: Alianza.

- (1978): «El proteccionismo de los trigueros castellanos y la naturaleza del poder político en la Restauración». Cuadernos Económicos del ICE 6, pp. 7-60.

Vicens Vives, J. (1969): Manual de Historia Económica de España. Barcelona: Vicens-Vives.

Vida Maritima, La (1901-1911 y 1915).

Zamora Terrés, J. (1996): El Sindicato Libre de la Marina Mercante, un intento de unidad sindical. Universitat Politècnica de Catalunya. Tesis Doctoral. 